\title{
Estrogens in the time of blood-thinners
}

\author{
Yosh Taguchi, MD, PhD, FRCSC
}

Former Program Director Urology, McGill University, Montreal, QC

Cite as: Can Urol Assoc J 2012;6(1):23-4. http://dx.doi.org/10.5489/cuaj.11140

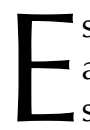
strogens were immensely popular to treat men with advanced prostate cancer and women who wanted to slow the aging process.

Estrogen, combined with progesterone, constituted hormone replacement therapy (HRT) and was considered beneficial for the cardiovascular system, bone health and emotional well-being. Its use has fallen into disfavour: in the case of prostate cancer due to complicating cardiac deaths; in replacement therapy because of possible breast cancer. This paper re-examines the use of estrogens in men with prostate cancer whose disease is no longer amenable to curative treatments, such as like ablative surgery or radiotherapy.

Charles Huggins first demonstrated the value of androgen deprivation therapy (ADT) long before it was called that. He showed that bilateral orchiectomy (quickly) and estrogen (by mouth, more slowly) over time eliminated testosterone from the body and improved the health of men with advanced prostate cancer. This seminal contribution was rightfully recognized and Huggins (along with Hodges) was awarded the Nobel Prize for Medicine in 1966. ${ }^{1}$

Surgical orchiectomy remains the quickest way (one hour) to achieve castrate level of testosterone, defined as readings under $0.5 \mathrm{ng} / \mathrm{mL}$, although $0.2 \mathrm{ng} / \mathrm{mL}$ is being promoted as the new standard. Arguments against surgical castration have been threefold: (1) it is too invasive; (2) it is irreversible; and (3) it is too devastating to the male psyche. It should be argued, however, that subcapsular orchiectomy under a local anesthetic is a minimally invasive, outpatient procedure that takes no more than 30 minutes. A testicular prosthesis can be inserted at the time if cosmetic results are important to the male psyche. Subcapsular orchiectomy is as effective as total orchiectomy as there are no Leydid cells in the capsule of the testicle. Furthermore, if the periodic presence of testosterone is ever proven worthwhile, testosterone can be administered at periodic intervals. Thus, the popularity of the luteinizing hormone-releasing hormone
(LHRH) agonists to achieve androgen deprivation must be due to the persuasive sales-pitch of pharmaceutical firms. After all, surgical orchiectomy costs a fraction of the annual cost of the LHRH agonists.

The LHRH agonists work to achieve castrate levels of testosterone in 3 weeks. Initially, however, there is a surge of testosterone, called a flare, which can be suppressed with a 2-week pre-treatment with an anti-androgen, such as bicalutimide, $50 \mathrm{mg}$ orally, administered daily. There is little evidence to support the superiority of one LHRH agonist over another. Some men prefer subcutaneous injections over intramuscular, or treatments every 4 to 6 months instead of every 1 to 3 months. The introduction of a LHRH antagonist (degarelix, which achieves castrate level testosterone in 3 days with no need for priming with anti-androgens) will compete for this market, although monthly subcutaneous injections are necessary. $^{2}$

Estrogen, which antedated the use of the LHRH agonists, achieves castrate level of testosterone in 2 weeks. The fluid retention, increased risks of phlebitis and deaths from pulmonary embolism occurred with higher doses of estrogens (3 to $5 \mathrm{mg}$ ) than with the lower does (1 to $3 \mathrm{mg}$ ). ${ }^{3}$ The Veterans Administration Study revealed the effectiveness of diethylstilbestrol (DES) in treating prostate cancer, but the cardiovascular side effects (infarcts, cardiovascular accidents, venous thrombosis and pulmonary embolism) often made patients in the treatment arm worse than those who had no treatment at all. The risks were higher with larger doses of DES (i.e., $5 \mathrm{mg}$ ), but when DES was dosed as low as $1 \mathrm{mg}$, cardiovascular complications occurred at an increased frequency. ${ }^{4}$ DES is no longer available. But estrogen, along with blood thinners, like acetylsalicylic acid (ASA), clopidogrel or warfarin, has never been adequately studied and deserves another study.

Smith and colleagues studied 21 patients on $1 \mathrm{mg}$ of DES and no blood thinners and found thrombotic events in 1 patient (5\%). ${ }^{5}$ Klotz and colleagues placed 32 patients on 2 to $3 \mathrm{mg}$ DES along with warfarin $1 \mathrm{mg}$ and found thromboembolic events in $28 \%$ of the subjects. ${ }^{6}$ Jazieh and col- 
leagues studied 14 patients on 3 mg DES with enough warfarin to achieve an international normalized ratio of 1.8 to 2.0; the authors reported no instance of thrombotic events. ${ }^{7}$ Clearly, estrogen with blood-thinners deserves further investigation. There is, however, an even more compelling reason why estrogens should be re-examined.

The aging male loses $1 \%$ of his total bone mass every year, but a male on ADT loses $4.5 \%{ }^{8}$ The rate of bone loss after the first year is less certain, but $50 \%$ of men on ADT have osteoporosis after 4 years, and $80 \%$ are osteoporotic after 10 years. Osteoporosis is defined by bone density studies where the loss is reported in terms of the amount of deviation from normal, with a test value of minus 2.5 or more constituting osteoporosis.

Weight-bearing exercises and supplemental calcium and vitamin $\mathrm{D}$ can reverse the bone loss as much as $0.5 \%$ to $2.5 \% .{ }^{8}$ If the loss is $4.5 \%$, exercise and supplements are not enough.

To date, the answer to this problem is bisphosphonates, which slow the rate of bone breakdown. The oral form, such as alendronate, along with vitamin $\mathrm{D}$ and calcium, has been widely prescribed to postmenopausal women. Curiously, the oral bisphosphonates have not been approved for men on ADT. Intravenous bisphosphonates, such as zoledronic acid, has been shown to treat the osteoporosis, but it is expensive (\$600.00 per month). ${ }^{9}$ The drug is covered in Quebec, Canada, only in patients with evidence of progressing bone metastases.

Intravenous zoledronic acid will be challenged by the subcutaneous denosumab, a monoclonal antibody that targets a rank ligand protein involved in normal bone breakdown. In a double-blind, head-to-head contest, denosumab won in terms of skeletal-related events, defined as fracture, nerve compression, need for surgery or need for radiotherapy. Priced right, denosumab should do well, but it is likely to be priced in the same range as zoledronic acid. ${ }^{10}$

Might there be a valid less expensive solution? Perhaps!

The hormone that builds bone in men (and women) is estrogen. ${ }^{8,11}$ But men on ADT have an $80 \%$ drop in their estrogen level. ${ }^{8}$ The reason seems obvious. Estrogen is derived from testosterone in the presence of aromatase. In fact, women on an aromatase inhibitor are more likely to have osteoporosis. ${ }^{12}$ If testosterone is depressed to minute levels, the estrogen must be lowered as well. A small amount of estrogen, perhaps $1 \mathrm{mg}$ of estradiol daily, may be all that is needed to maintain healthy bones.

The active estrogen in the body is estradiol. Conjugated estrogen, like premarin, or synthetic estrogen, like DES, must be converted into estradiol to become active. Estradiol is available in pill form or as a skin patch, at a cost of $\$ 0.25$ per mg. With blood-thinners of one kind or another at different dosages, estrogen deserves to be considered to prevent osteoporosis for men on ADT. Its role in managing prostate cancer deserves a second look. In a time of escalating health care costs, estrogen, with its dual role, deserves reconsideration. A one-year study that looks at bone mineral density before and one year after launching ADT with or without estradiol can easily be carried out. The study can determine the relative merit of ASA, clopidogrel, warfarin or other products to diminish the risk of thrombo-embolism. The merit of estrogen therapy can be ascertained or discredited. After all, it is surprising that despite the positive results with DES, with respect to prostate cancer, ${ }^{13}$ and equally good results with premarin, ${ }^{14}$ this treatment modality has not gained a foothold in urologic practice.

Readers may recognize the title of this piece. It was adapted from Gabriel Garcia Marquez's classic, Love in the Time of Cholera. His description of obstructive prostate symptoms is more colourful than anything in medical literature.

\section{Competing interests: None.}

This paper has been peer-reviewed.

\section{References}

1. Huggins C, Hodges C. Studies on prostate cancer 1. The effect of castration, of estrogen and of androgen injection on serum phosphatases in metastatic carcinoma of the prostate. Cancer Res 1941;1:293.

2. Klotz L, Boccon-Gibod L, Shore ND, et al. The efficacy and safety of degarelix: a 12-month, comparative, randomized, open-label, parallel-group phase 111 study in patients with prostate cancer. BJU Int 2008;102:1531-8. http://dx.doi.org/10.1111/j.1464-410X.2008.08183.x

3. Byar DP, Corle DK. Hormone therapy for prostate cancer: results of the Veterans Administration Cooperative Urological Research Group studies. NCI Monogr 1988;7:165-70.

4. Blackard CE. The Veterans' Administration Cooperative Urological Research Group studies of carcinoma of the prostate: a review. Cancer Chemother Rep 1975;59:225-7.

5. Smith DC, Redman BG, Flaherty LE, et al. A Phase 11 Trial of Oral DES as a second-line Hormonal Agent in Advanced Prostate Cancer. Urology 1998;52:257-60. http://dx.doi.org/10.1016/S00904295(98)00173-3

6. Klotz L, McNeil I, Fleshner N. A Phase 1-2 trial of diethylstilbestrol plus low dose warfarin in advanced prostate carcinoma. J Urol 1999;161:169-72. http://dx.doi.org/10.1016/S0022-5347(01)62089-5

7. Jazieh AR, Munshi NC, Muirhead M, et al. Clinical efficacy of Diethylstilbestrol treatment in post-orchiectomy progressive prostate cancer. Proc AACR 1994;35:233.

8. Higano CS. Androgen-deprivation-therapy-induced fractures in men with nonmetastatic prostate cancer: what do we really know? Nat Clin Pract Urol 2008;5:24-34.

9. Aapro M, Abrahamsson PA, Body JJ, et al. Guidance on the use of bisphosphonates in solid tumours: recommendations of am international expert panel. Ann Oncol 2008;19:420-32. http://dx.doi.org/10.1093/ annonc/mdm442

10. Fizazi K, Carducci M, Smith M, et al. Denosumab versus zoledronic acid for treatment of bone metastases in men with castration-resistant prostate cancer: a randomized, double-blind study. Lancet 2011;377:81322. http://dx.doi.org/10.1016/50140-6736(10)62344-6

11. Vandenput L, Ohlsson C. Estrogens as regulators of bone health in men. Nat Rev Endocrinol 2009;5:43743

12. Mokbel K. The evolving role of aromatase inhibitors in breast cancer. Int J Clin Oncol 2002; 7:279-83.

13. Scherr D, Pitts WR Jr, Vaughan ED Jr. Diethylstilboestrol revisited: Androgen deprivation osteoporosis and prostate cancer. J Urol 2002; 167:535-8. http://dx.doi.org/10.1016/S0022-5347(01)69080-3

14. Pomerantz M, Manola J, Taplin ME, et al. Phase 11 study of low dose and high dose conjugated estrogen for androgen independent prostate cancer. J Urol 2007;177:2146-50. http://dx.doi.org/10.1016/i. juro.2007.01.119

Correspondence: Dr. Yosh Taguchi, Royal Victoria Hospital, 687 Pine Ave, West, S6.86 Montreal, QC H3A 1A1; ytaguchi@allstream.net 